\title{
International alliance to share genomic data
}

$\mathrm{G}$ enomic medicine is about to take off in such a sudden, life-changing way that international scientists are comparing the current juncture to the primitive Internet days of the early 1990s.

The nascent Global Alliance to Enable Responsible Sharing of Genomic and Clinical Data, announced June 3, claims it will be modeled on the World Wide Web Consortium, which established universal protocols to create the Internet we have today from a series of closed, independent networks.

"We're talking about enabling the responsible sharing of data, not mandating it and certainly not building one, big centralized database," says Peter Goodhand, executive lead, International Partnerships at the Ontario Institute for Cancer Research, a founding member of the alliance.

The alliance's raison d'être is that technological advances in the last decade - including genetic sequencing innovations and cloud computing have made it theoretically possible to conduct massive-scale, international genetic research, but parochial policies and the development of silo systems stand in the way.

However, most discoveries in genomic research can only be made with the involvement of numerous institutions in multiple countries, due to the breadth of genetic variations and differing patient outcomes associated with a single disease, according to Dr. Katherine Siminovitch, director of Personalized Genomics and Innovative Medicine at Mount Sinai Hospital, which is a member of the Global Alliance.

"You may need 10000 patients with such and such disease, and even if it's a common disease, it's very unlikely any one centre is looking after 10000 cases," she explains. However, if the alliance facilitates the combination of many centres' data, it can be possible to draw conclusions, Siminovitch says.

The repercussions of collaborative research will affect everything from cus-

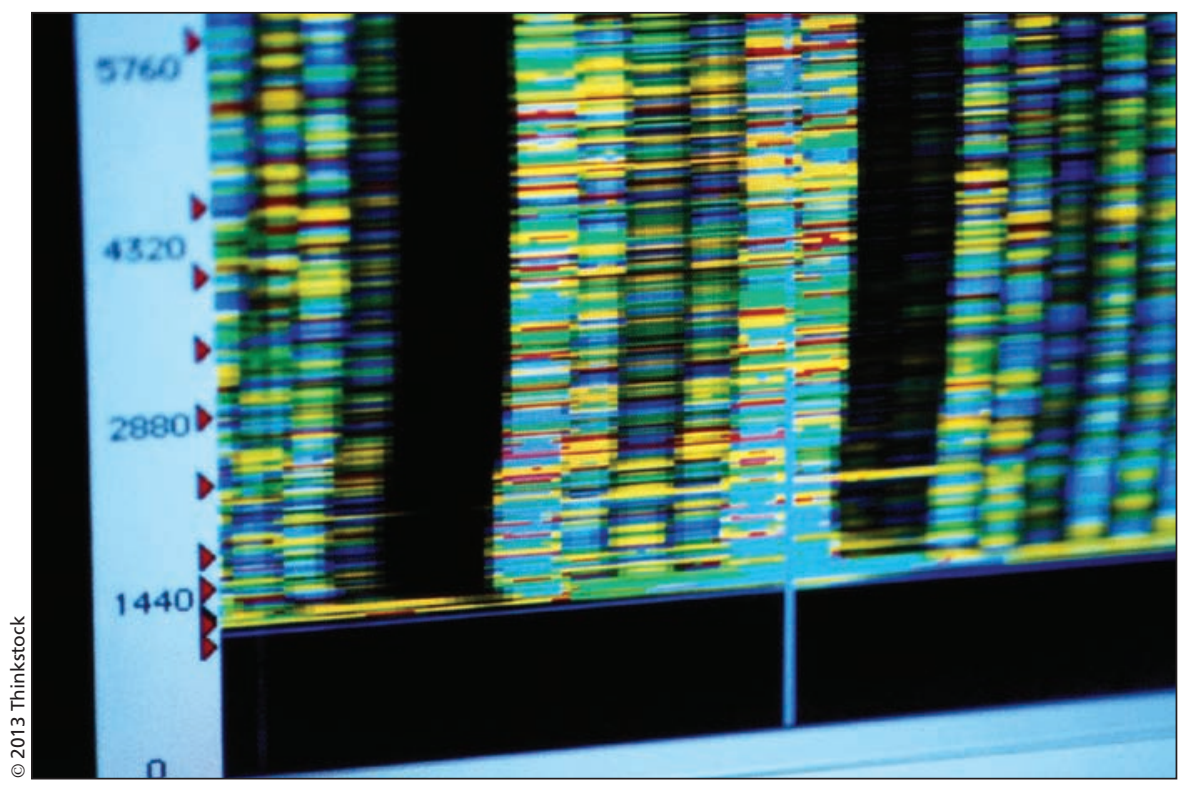

Most discoveries in genomic research can only be made with the involvement of numerous institutions in multiple countries, due to the breadth of genetic variations and differing patient outcomes associated with a single disease, says one expert involved in the new alliance.

tomized cancer treatment to the unprecedented tracking of infectious agents, according to the alliance's white paper. And it's all possible because the cost of genetic sequencing has plummeted in a decade.

"I could now do your whole exome [part of the DNA that codes for proteins] for less than $\$ 1000$," says Siminovitch. "And that's down from the billions of dollars that it would have cost to do it in the year 2000."

Siminovitch is hopeful that genetic research will help her understand why the first drug she gives for rheumatoid arthritis, methotrexate, doesn't work on $30 \%$ of her patients. "It takes six months to a year to realize that. If I can test for the genetic reason why they don't respond, I can predict that ahead of time and treat the patient appropriately," she says.

More than 70 organizations in over 40 countries have signed a nonbinding "letter of intent" to build the alliance. In the fall, according to Goodhand, representatives of these organizations, which include universities, hospitals, research centres and advocacy groups, will have the opportunity to make their participation formal by signing a memorandum of understanding.

Private companies are also welcome to join the alliance, so long as they agree to its principles including transparency, collaboration and accountability. "For profit companies are a huge component here, whether it be pharmaceutical, biotech or information technology research," says Goodhand.

Before the formal memorandum of understnaind makes the alliance official, expert working groups will attempt to establish technical, ethical and legal best practices, says Goodhand.

One aim of the alliance, for example, is to encourage research institutions to allow legal consent to be portable, so patients can consent to their clinical data being shared across borders. While the Human Genome Project saw researchers sharing genetic research internationally, Goodhand says, "none of the projects before have had to deal with the issue of sharing clinical information alongside genomic information." 
"There are ethics committees who think that a broad consent is not valid, whereas broad consent is valid, if patients are properly informed," says Bartha Knoppers, a lawyer expert on the ethical aspects of genetics at McGill University in Montréal, Quebec, who contributed to the alliance's white paper.

However, other legal experts are worried that an overly urgent push to launch cross-border genomic medicine research could lead to unethical practices.

Since "the ultimate goal of the alliance is to create the largest possible bio-repository," whether centralized or decentralized, "where does ethics and individual welfare and autonomy come in as a priority?" asks Maxwell Mehlman, director of the Law-Medicine Center at Case Western Reserve University in Cleveland, Ohio.

The alliance will also lobby for harmonized national policies so that clinical data can be shared across the world. Technology will need to be developed to allow research across different storage and analysis systems - much like third-party application creators can communicate with major smartphone systems, Goodhand explains.

One of the biggest barriers to the research may be a surprising one, how- ever: ego. The rapid sharing and analysis of data will make it difficult to pinpoint individual or institutional contributions for accolades. "We'll need to move away from the genius scientist model to a collaborative, international model," says Knoppers.

And, just like gene sequencing, that move will represent a paradigm shift in research, says Siminovitch. "People can't be parochial. They have to be into the idea of sharing and letting everybody benefit simultaneously." Wendy Glauser, Toronto, Ont.

CMAJ 2013. DOI:10.1503/cmaj.109-4532 